\title{
PERBANDINGAN METODE SINGLE EXPONENTIAL SMOOTHING DAN MOVING AVERAGE PADA PERAMALAN PENJUALAN PRODUK MINYAK GORENG DI PT TUNAS BARU LAMPUNG
}

\author{
Niken Chaerunnisa ${ }^{1 *}$ dan Ade Momon ${ }^{2}$ \\ ${ }^{1,2}$ Program Studi Teknik Industri, Fakultas Teknik, Universitas Singaperbangsa Karawang \\ Jl. H. S. Ronggowaluyo Teluk Jambe, Karawang, Indonesia 41361 \\ *email: niken10chaerunnisa@gmail.com
}

\begin{abstract}
PT Tunas Baru Lampung is a company that produces palm cooking oil products under the Rose Brand brand. In product sales, companies sometimes experience ups and downs. Based on the sales data from Rose Brand Cooking Oil, the size of $1 \mathrm{~L}$ has fluctuated or in each period it changes and is not always boarding. Even though product sales are one of the important things to be evaluated from time to time on an ongoing basis. To predict future sales, forecasting is done. The forecasting method used is Double Exponential Smoothing and Moving Average. The method of accuracy will be compared using MSE, MAD, and MAPE. The results showed a comparison of the accuracy and the smallest error value in each method. By using the weight values 0.1, 0.3, 0.4, 0.5, 0.6, 0.7, and 0.8 on the Single Exponential Smoothing method the weight value is 0.8 or $\alpha=0.8$, namely MSE of 250,570,764.80, MAD of 12,922.32 and MAPE of 33.55 Then, using the movement value $n=3$ in the Moving Average method has an accuracy of 438,980,942.75 MSE, 18,142.14 MAD, and 41.37 MAPE. After comparing the accuracy of the two methods, the Single Exponential Smoothing method is the best method to predict sales of Rose Brand 1 L Cooking Oil products.
\end{abstract}

Keywords: Forecasting, MSE, MAD, MAPE, Product

\section{Pendahuluan}

PT Tunas Baru Lampung merupakan sebuah perusahaan di bawah naungan PT Budi Makmur Perkasa yang memproduksi produk minyak goreng sawit dengan merek Rose Brand. Minyak goreng merupakan salah satu kebutuhan sebagai alat untuk mengolah bahan-bahan makanan baik pada rumah tangga maupun industri makanan. Tetapi terkadang perusahaan dapat mengalami naik turun pada penjualan produk. Penjualan produk merupakan salah satu hal yang pentig untuk dievaluasi dari waktu ke waktu secara terusmenerus. Berdasarkan data penjualan produk Minyak Goreng Rose Brand ukuran 1 L mengalami fluktuasi atau pada setiap periodenya berubah-ubah dan tidak selalu konstan. Menurut Tistiawan \& Andini (2019), faktor-faktor yang baiasanya mempengaruhi penjualan diantaranya adalah promo yang berlangsung, kenaikan harga, pengembalian barang dari toko atau return penjualan dan lain sebagainya. Maka dari itu, perusahaan harus dapat meramalkan kuantiti penjualan untuk waktu yang akan datang.

Menurut Gustriansyah et al. (2017), peramalan kuantiti penjualan adalah kegiatan yang dilakukan agar dapat memperkirakan besarnya penjualan produk oleh produsen atau distributor pada periode waktu dan wilayah pemasaran tertentu yang merupakan suatu bagian dari fungsi manajemen sebagai salah satu contributor kesuksesan suatu perusahaan.

Perdana et al. (2012), menyebutkan bahwa peramalan diperlukan karena adanya perbedaan kesenjangan waktu (timelag) antara kesadaran akan dibutuhkannya suatu kebijakan yang baru dengan waktu pelaksanaan kebijakan tersebut.

Berdasarkan data fluktuatif pada PT Tunas Baru Lampung yang disebutkan di atas yaitu data berfluktuatif tersebut akan dilakkan smoothig karena menurut Witanti (2009), smoothing ialah salah satu cara yang digunakan untuk menghilangkan noise pada data yang berfluktuatif.

Metode peramalan yang digunakan pada penelitian ini adalah Single Exponential Smoothing dan Moving Average. Metode tersebut akan dibandingkan tingkat keakurasiannya menggunakan MSE, MAD dan MAPE serta diambil metode terbaik dengan hasil yang lebih akurat.

2. Landasan Teori

2.1. Metode Single Exponential Smoothing 
Single exponential smoothing ini merupakan peramalan yang digunakan untuk jangka pendek atau biasanya hanya untuk satu bulan ke depan. Model ini mengasumsikan bahwa data yang berfluktuasi berada pada nilai mean yang tetap, tanpa adanya trend ataupun pola pertumbuhan yang konsisten (Makridakis, 1999). Menurut Ishak (2010:126), metode single exponential smoothing ialah nilai yang diramalkan pada periode $t+1$ yang antara lain merupakan nilai aktual pada periode $\mathrm{t}$ ditambah dengan penyesuaian yang berasal dari kesalahan nilai ramalan yang terjadi pada periode tersebut. Di bawah ini merupakan rumus single exponential smoothing:

$\mathrm{F}_{\mathrm{t}+1}=\alpha \mathrm{X}_{\mathrm{t}}+(1-\alpha) \mathrm{F}_{\mathrm{t}}$

Dimana:

$F_{t}$ atau $S^{\prime} t=$ Peramalan pada periode $t$

$\mathrm{F}_{\mathrm{t}+1}=$ Peramalan pada waktu $\mathrm{t}+1$

$\alpha=$ Konstanta perataan antara 0 sampai 1

$\mathrm{X}_{\mathrm{t}}+(1-\alpha)=$ Nilai aktual time series

\subsection{Metode Moving Average}

Menurut Pangestu Subagyo (1986), peramalan moving average ialah metode peramalan yang dilakukan dengan mengambil data atau sekelompok nilai pengamatan, lalu sekelompok nilai tersebut dicari rata-ratanya. Rata-rata yang didapatkan tersebut digunakan sebagai peramalan untuk periode selanjutnya. Metode moving average ini memiliki karakteristik khusus, diantaranya adalah:

a. Membutuhkan data historis dengan jangka tertentu dalam menentukan peramalan yang akan datang.

b. Jangka waktu yang semakin panjang membuat efek pelicinan semakin terlihat dalam peramalan atau akan menghasilkan moving average yang semakin halus.

Berikut merupakan rumus persamaan matematis single moving average:

$\mathrm{Mt}=\mathrm{Ft}+1$

$=\frac{Y_{t}+Y_{t-1}+Y_{t-2}+\ldots+Y_{t-(n+1)}}{n}$

Dengan:

$\mathrm{Mt}=$ Moving Average untuk periode $\mathrm{t}$

$\mathrm{Yt}=$ Nilai Riil pada periode ke- $\mathrm{t}$

$\mathrm{Ft}+1=$ Ramalan untuk periode $\mathrm{t}+1$

\subsection{Pengukuran Akurasi}

Menurut Yamit (2008), tingkat kesalahan dalam perhitungan peramalan dapat dihitung dengan menggunakan Mean Absolute Deviation (MAD) dan Mean Squared Error (MSE). Tingkat kesalahan yang dihitung dengan metode-metode tersebut dalam perhitungan peramalan dapat memberikan ukuran ketepatan untuk membandingkan metode peramalan alternatif yang mungkin akan digunakan.

Mean Absolute Deviation (MAD) merupakan nilai absolute rerata dari kesalahan dalam peramalan yang hasilnya mengabaikan tanda positif maupun negative. Rumus dari MAD tersebut adalah, sebagai berikut:

$\mathrm{MAD}=\sum|A t-F t|$

Dengan:

$\sum=$ Jumlah

$\mathrm{Ft}=$ Ramalan periode ke- $\mathrm{t}$

$\mathrm{At}=$ Data pengamatan periode ke- $\mathrm{t}$

Mean Squared Error (MSE) merupakan ratarata perbedaan kuadrat antara nilai yang diamati, lalu dijumlahkan dan ditambahkan dengan jumlah yang diamati. Pendekatan ini memperkuat pengaruh besar karena kesalahan-kesalahan tersebut dikuadratkan. Berikut merupakan rumus dari MSE:

$\mathrm{MSE}=\frac{\sum e_{i}^{2}}{n}$

Selain itu, terdapat juga Mean Absolute Percentage Error (MAPE) yang merupakan perhitngan menggunakan kesalahan absolute pada setiap periode lalu dibagi dengan nilai pengamatan yang nyata untuk periode tersebut. Semakin kecil nilai MAPE maka semakin akurat pula hasil atau teknik peramalan yang dilakukan dan sebaliknya (Aritonang, 2002). Berikut merupakan rumus untuk menentukan nilai MAPE:

MAPE $=\frac{100}{n} \sum_{t=1}^{n} \frac{\left|X_{t}-F_{t}\right|}{X_{t}}$

Dengan:

$F_{t}=$ Nilai ramalan untuk periode waktu ke-t

$X_{t}=$ Nilai aktual pada periode waktu ke-t

$\mathrm{n}=$ Banyaknya data hasil peramalan 


\section{Metode Penelitian}

Pada peletian ini, metode-metode yang digunakan antara lain, sebagai berikut:

\subsection{Observasi}

Pada proses observasi, peneliti melakukan pengamatan langsung atau mengunjungi langsung ke tempat peneltian yaitu, PT Tunas Baru Lampung dan mencatat hal-hal penting yang diperlukan selama melakukan pengamatan.

\subsection{Wawancara}

Wawancara dilakukan dengan proses tanya jawab bersama beberapa narasumber yaitu pekerja di PT Tunas Baru Lampung yang bertujuan untuk memperoleh data-data yang dibutuhkan.

\subsection{Studi Literatur}

Studi pustaka yang dilakukan peneliti adalah dengan membaca dan mempelajari jurnal-jurnal terdahulu yang berkaitan dengan permasalahan yang diteliti dan buku-buku.

\subsection{Teknik Analisis Data}

Analisis data pada penelitian ini menggunakan perhitungan secara kuantitatif dengan menggunakan metode atau rumus-rumus yang telah ditentukan sebagai penganalisa data sesuai dengan masalah yang ada. Metode tersebut adalah Single Exponential Smoothing dan Moving Average serta mengukur akurasi peramalan menggunakan MAD, MSE, dan MAPE.

\section{Hasil dan Pembahasan}

Data yang digunakan untuk melakukan peramalan pada penelitian ini adalah data history penjualan produk minyak goreng kemasan $1 \mathrm{~L}$ dari tahun Januari 2019 sampai dengan Desember 2020. Adapun data-data tersebut adalah, sebagai berikut:

Tabel 1. Data Penjualan Produk Minyak Goreng Rose Brand 1 L 2019-2020

\begin{tabular}{lcc}
\hline \multicolumn{1}{c}{ Periode } & $\mathbf{2 0 1 9}$ & $\mathbf{2 0 2 0}$ \\
\hline Januari & 18899 & 68615 \\
Februari & 16500 & 70880 \\
Maret & 47060 & 91813 \\
April & 55249 & 89918 \\
Mei & 68429 & 73279 \\
Juni & 42958 & 73244 \\
Juli & 43560 & 54055 \\
Agustus & 30631 & 33412 \\
September & 26124 & 18500 \\
Oktober & 41172 & 49572 \\
November & 37256 & 32020 \\
Desember & 35144 & 52170 \\
\hline
\end{tabular}

Sumber: Pengolahan Data
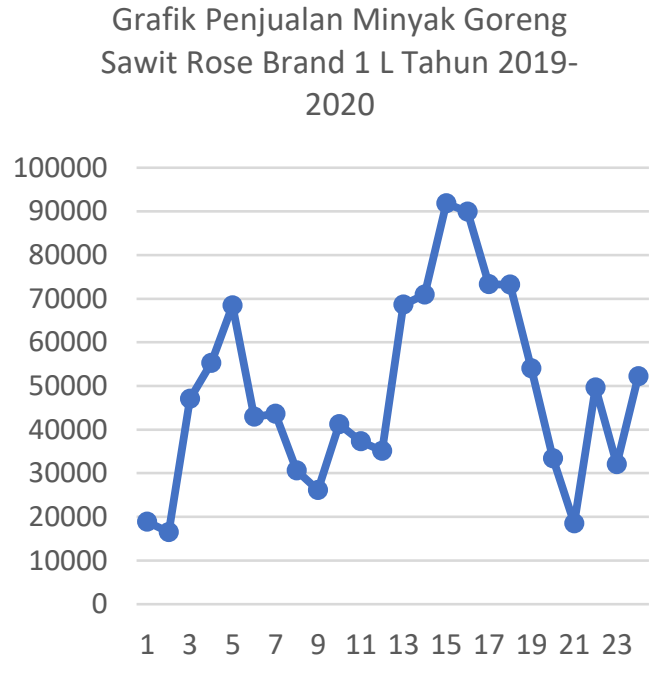

Gamar 1. Grafik Penjualan Minyak Goreng

Sawit Rose Brand 1 L Tahun 2019-2020

Sumber: Pengolahan Data

Berdasarkan grafik di atas, penjualan pada produk Minyak Goreng Rose Brand $1 \mathrm{~L}$ cenderung berfluktuasi. Untuk mengetahui penjualan pada waktu ke depan maka pada penelitian ini dilakukan dengan membandingkan peramalan menggunakan metode Single Exponential Smoothing dan Moving Average.

\subsection{Single Exponential Smoothing}

Pada peramalan menggunakan metode Single Exponential Smoothing dilakukan dengan $\alpha$ 0.1, 0.3, 0.4, 0.5, 0.6, 0.7, dan 0.8. Dari hasil perhitungan MSE yang dilakukan, didapatkan hasil MSE terkecil pada $\alpha$ 0,8. Berikut hasil perhitungan perbandingan MSE menggunakan Excel pada keseluruhan data yang telah dihitung dengan alfa yang sudah disebutkan di atas.

Tabel 2. Hasil Perbandingan Nilai MSE, MAD dan MAPE Pada Metode Single Exponential Smoothing

\begin{tabular}{ccccr}
\hline No. & Metode & MSE & MAD & MAPE \\
\hline $\mathbf{1}$ & $\alpha=0,1$ & 506698183,01 & 17520,19 & 35,49 \\
\hline $\mathbf{3}$ & $\alpha=0,3$ & 442277689,67 & 16176,21 & 37,89 \\
\hline $\mathbf{4}$ & $\alpha=0,4$ & 397158117,61 & 16362,21 & 38,14 \\
\hline $\mathbf{5}$ & $\alpha=0,5$ & 360469200,43 & 16179,20 & 37,38 \\
\hline $\mathbf{6}$ & $\alpha=0,6$ & 331758214,65 & 15705,38 & 36,02 \\
\hline $\mathbf{7}$ & $\alpha=0,7$ & 311078386,76 & 15113,01 & 34,49 \\
\hline $\mathbf{8}$ & $\alpha=0,8$ & 250570764,80 & 12922,32 & 33,55 \\
\hline
\end{tabular}

Sumber: Pengolahan Data 
Dengan perhitungan metode single exponential smoothing menggunakan excel, sebagai berikut:

Tabel 3. Perhitungan Peramalan Single Exponential Smoothing Menggunakan $\alpha=0,8$

\begin{tabular}{rrrrrr}
\hline No & Xt & S't & \multicolumn{1}{|c|}{ Error| } & \multicolumn{1}{c}{ Error $^{\wedge} \mathbf{2}$} & \multicolumn{1}{c}{ APE } \\
\hline $\mathbf{1}$ & 29427 & 18899 & & & \\
$\mathbf{2}$ & 22330 & 27321 & 4991,40 & 24914073,96 & 22,35 \\
$\mathbf{3}$ & 44862 & 23328 & 21533,72 & 463701097,04 & 48,00 \\
$\mathbf{4}$ & 29251 & 40555 & 11304,26 & 127786203,71 & 38,65 \\
$\mathbf{5}$ & 50061 & 31512 & 18549,15 & 344070921,20 & 37,05 \\
$\mathbf{6}$ & 21100 & 46351 & 25251,17 & 637621598,49 & 119,67 \\
$\mathbf{7}$ & 32732 & 26150 & 6581,77 & 43319643,05 & 20,11 \\
$\mathbf{8}$ & 26321 & 31416 & 5094,65 & 25955426,11 & 19,36 \\
$\mathbf{9}$ & 35793 & 27340 & 8453,07 & 71454403,21 & 23,62 \\
$\mathbf{1 0}$ & 43211 & 34102 & 9108,61 & 82966851,33 & 21,08 \\
$\mathbf{1 1}$ & 54157 & 41389 & 12767,72 & 163014746,15 & 23,58 \\
$\mathbf{1 2}$ & 50249 & 51603 & 1354,46 & 1834549,53 & 2,70 \\
$\mathbf{1 3}$ & 54438 & 50520 & 3918,11 & 15351577,45 & 7,20 \\
$\mathbf{1 4}$ & 29536 & 53654 & 24118,38 & 581696167,84 & 81,66 \\
$\mathbf{1 5}$ & 46864 & 34360 & 12504,32 & 156358127,61 & 26,68 \\
$\mathbf{1 6}$ & 82990 & 44363 & 38626,86 & 1492034689,79 & 46,54 \\
$\mathbf{1 7}$ & 58014 & 75265 & 17250,63 & 297584132,78 & 29,74 \\
$\mathbf{1 8}$ & 56758 & 61464 & 4706,13 & 22147616,33 & 8,29 \\
$\mathbf{1 9}$ & 54235 & 57699 & 3464,23 & 12000855,41 & 6,39 \\
$\mathbf{2 0}$ & 59760 & 54928 & 4832,15 & 23349721,79 & 8,09 \\
$\mathbf{2 1}$ & 69685 & 58794 & 10891,43 & 118623269,16 & 15,63 \\
$\mathbf{2 2}$ & 56580 & 67507 & 10926,71 & 119393074,48 & 19,31 \\
$\mathbf{2 3}$ & 31270 & 58765 & 27495,34 & 755993873,50 & 87,93 \\
$\mathbf{2 4}$ & 23280 & 36769 & 13489,07 & 181954970,40 & 57,94 \\
\hline & & & 12922,32 & 250570764,80 & 33,55 \\
\hline & & & $\mathbf{M A D}$ & $\mathbf{M S E}$ & $\mathbf{M A P E}$ \\
\hline & & & & & \\
\hline
\end{tabular}

\subsection{Moving Average}

Sumber: Pengolahan Data

Berikut merupakan hasil perhitungan peramalan serta MAD, MSE, dan MAPE menggunakan Excel. Hasil yang didapatkan pada Tabel 4. tersebut antara lain MAD sebesar 18.142,14, MSE sebesar 438.980.942,75 dan MAPE sebesar $41,37 \%$.

Tabel 4. Hasil Perhitungan Peramalan dan MSE Menggunakan metode Moving Average

\begin{tabular}{rrrrrcr}
\hline $\mathbf{t}$ & Demand & $\begin{array}{c}\text { MA } \\
\mathbf{( 3 )}\end{array}$ & Error & $\mid$ Error| & Error^2 & APE \\
\hline $\mathbf{1}$ & 18899 & & & & & \\
$\mathbf{2}$ & 16500 & & & & & \\
$\mathbf{3}$ & 47060 & & & & & \\
$\mathbf{4}$ & 55249 & 27486 & 27762,67 & 27762,67 & 770765660,44 & 50,25 \\
$\mathbf{5}$ & 68429 & 39603 & 28826,00 & 28826,00 & 830938276,00 & 42,13 \\
$\mathbf{6}$ & 42958 & 56913 & - & 13954,67 & 194732721,78 & 32,48 \\
& & & 13954,67 & & & \\
$\mathbf{7}$ & 43560 & 55545 & - & 11985,33 & 143648215,11 & 27,51 \\
$\mathbf{8}$ & 30631 & 51649 & - & 21018,00 & 441756324,00 & 68,62 \\
$\mathbf{9}$ & 26124 & 39050 & - & 12925,67 & 167072858,78 & 49,48 \\
& & & 12925,67 & & & \\
\hline
\end{tabular}




\begin{tabular}{rrrrrrr}
$\mathbf{1 0}$ & 41172 & 33438 & 7733,67 & 7733,67 & 59809600,11 & 18,78 \\
$\mathbf{1 1}$ & 37256 & 32642 & 4613,67 & 4613,67 & 21285920,11 & 12,38 \\
$\mathbf{1 2}$ & 35144 & 34851 & 293,33 & 293,33 & 86044,44 & 0,83 \\
$\mathbf{1 3}$ & 68615 & 37857 & 30757,67 & 30757,67 & 946034058,78 & 44,83 \\
$\mathbf{1 4}$ & 70880 & 47005 & 23875,00 & 23875,00 & 570015625,00 & 33,68 \\
$\mathbf{1 5}$ & 91813 & 58213 & 33600,00 & 33600,00 & 1128960000,00 & 36,60 \\
$\mathbf{1 6}$ & 89918 & 77103 & 12815,33 & 12815,33 & 164232768,44 & 14,25 \\
$\mathbf{1 7}$ & 73279 & 84204 & - & 10924,67 & 119348341,78 & 14,91 \\
& & & 10924,67 & & & \\
$\mathbf{1 8}$ & 73244 & 85003 & - & 11759,33 & 138281920,44 & 16,06 \\
$\mathbf{1 9}$ & 54055 & 78814 & - & 24758,67 & 612991575,11 & 45,80 \\
& & & 24758,67 & & & \\
$\mathbf{2 0}$ & 33412 & 66859 & - & 33447,33 & 1118724107,11 & 100,11 \\
& & & 33447,33 & & & \\
$\mathbf{2 1}$ & 18500 & 53570 & - & 35070,33 & 1229928280,11 & 189,57 \\
& & & 35070,33 & & & \\
$\mathbf{2 2}$ & 49572 & 35322 & 14249,67 & 14249,67 & 203053000,11 & 28,75 \\
$\mathbf{2 3}$ & 32020 & 33828 & $-1808,00$ & 1808,00 & 3268864,00 & 5,65 \\
$\mathbf{2 4}$ & 52170 & 33364 & 18806,00 & 18806,00 & 353665636,00 & 36,05 \\
\hline & & & & 18142,14 & 438980942,75 & 41,37 \\
\hline & & & & MAD & MSE & MAPE \\
\hline
\end{tabular}

Sumber: Pengolahan Data

\subsection{Perbandingan Keakuratan}

Setelah dilakukan perhitungan peramalan dan keakuratan peramalan dari setiap metode, maka yang akan dilakukan selanjutnya adalah membandingkan MAD, MSE dan MAPE dari kedua metode. Berikut merupakan tabel ringkasan dan perbandingannya:

Tabel 5. Perbandingan MSE Metode Moving Average dan Single Exponential Smoothing

\begin{tabular}{rrrr}
\hline \multicolumn{4}{c}{ Verifikasi Data Peramalan } \\
\hline \multirow{2}{*}{ t } & Data & \multicolumn{2}{c}{ Ramalan } \\
\cline { 3 - 4 } $\mathbf{1}$ & Demand & MA (3) & SES 0,8 \\
$\mathbf{2}$ & 18899 & & \\
$\mathbf{3}$ & 16500 & & 18899 \\
$\mathbf{4}$ & 57060 & & 16740 \\
$\mathbf{5}$ & 55249 & 27486 & 44028 \\
$\mathbf{6}$ & 429429 & 39603 & 54127 \\
$\mathbf{7}$ & 43560 & 56913 & 66999 \\
$\mathbf{8}$ & 30631 & 55545 & 45362 \\
$\mathbf{9}$ & 26124 & 51649 & 43740 \\
$\mathbf{1 0}$ & 41172 & 39050 & 31942 \\
$\mathbf{1 1}$ & 37256 & 33438 & 26706 \\
$\mathbf{1 2}$ & 35144 & 32642 & 39725 \\
$\mathbf{1 3}$ & 68615 & 34851 & 37503 \\
$\mathbf{1 4}$ & 70880 & 37857 & 35380 \\
$\mathbf{1 5}$ & 91813 & 47005 & 65291 \\
& & 58213 & 70321
\end{tabular}

\begin{tabular}{rrrr}
$\mathbf{1 6}$ & 89918 & 77103 & 89664 \\
$\mathbf{1 7}$ & 73279 & 84204 & 89893 \\
$\mathbf{1 8}$ & 73244 & 85003 & 74940 \\
$\mathbf{1 9}$ & 54055 & 78814 & 73414 \\
$\mathbf{2 0}$ & 33412 & 66859 & 55991 \\
$\mathbf{2 1}$ & 18500 & 53570 & 35670 \\
$\mathbf{2 2}$ & 49572 & 35322 & 20217 \\
$\mathbf{2 3}$ & 32020 & 33828 & 46636 \\
$\mathbf{2 4}$ & 52170 & 33364 & 33482 \\
& MSE & $\mathbf{4 3 8 9 8 0 9 4 2 , 7 5}$ & $\mathbf{2 5 0 5 7 0 7 6 4 , 8 0}$ \\
\hline & MAD & $\mathbf{1 8 1 4 2 , 1 4}$ & $\mathbf{1 2 9 2 2 , 3 2}$ \\
\hline & MAPE & $\mathbf{4 1 , 3 7}$ & $\mathbf{3 3 , 5 5}$
\end{tabular}

Sumber: Pengolahan Data

Berdasarkan tabel di atas, MSE, MAD dan MAPE terkecil terdapat pada metode Single Exponential Smoothin $\alpha=0,8$ dengan MSE sebesar 250.570.764,80, MAD sebesar 12.922,32 dan MAPE sebesar 33,55. Sedangkan Moving Average menghasilkan MSE sebesar 438.980.942,75, MAD sebesar 18.142,14 dan MAPE sebesar 41,37.

\section{Kesimpulan}

Nilai akurasi pada setiap metode dapat dipengaruhi oleh penentuan nilai pergerakan dan nilai bobot yang digunakan. Dengan menggunakan niali bobot $0,1,0,3,0,4,0,5,0,6,0,7$ dan 0,8 pada 
metode Single Exponential Smoothing nilai bobot 0,9 atau $\alpha=0,8$ yaitu MSE sebesar 250.570.764,80, MAD sebesar 12.922,32 dan MAPE sebesar 33,55. Lalu, dengan menggunakan nilai pergerakan $\mathrm{n}=3$ pada metode Moving Average memiliki akurasi yaitu MSE sebesar 438.980.942,75, MAD sebesar 18.142,14 dan MAPE sebesar 41,37.

Setelah membandikan akurasi dari kedua metode tersebut, maka metode Single Exponential Smoothing sebagai metode terbaik untuk meramalkan penjualan produk Minyak Goreng Rose Brand $1 \mathrm{~L}$.

\section{Daftar Referensi}

Aritonang, R. (2002). Peramalan Bisnis. Jakarta: Ghalia Indonesia.

Gustriansyah, R., Indo, U., \& Mandiri, G. (2017). Analisis Metode Single Exponential Smoothing dengan Brown Exponential Smoothing pada Studi Kasus Memprediksi Kuantiti Penjualan Produk Farmasi ANALISIS METODE SINGLE EXPONENTIAL SMOOTHING DENGAN BROWN EXPONENTIAL SMOOTHING PADA STUDI KASUS. February, 6-11. https://www.researchgate.net

Ishak, Aulia. (2010). Manajemen Operasi. Yogyakarta: Graha Ilmu.

Makridakis, Spyros dan Wheelwright, Steven C. (1999). Metode dan Aplikasi Peramalan. Jakarta: Binarupa Aksara.

Perdana, F. R., Daryanto, S.Kom, M. K., \& Henny Wahyu, S. K. (2012). Perbandingan Metode DES (Double Exponential Smoothing) Pada Peramalan Penjualan Rokok (Studi Kasus Toko Utama Lumajang). 1110651142. http://repository.unmuhjember.ac.id

Subagyo, Pangestu. (1986). Forecasting Konsep dan Aplikasi. Yogyakarta: BPPE UGM.

Tistiawan, T. A., \& Andini, T. D. (2019). Pemanfaatan Metode Triple Exponential Smoothing Dalam. 13(1), 69-76. https://jurnal.stmikasia.ac.id

Witanti, A. (2009). Smoothing Data Fluktuatif Dengan Exponential Smoothing Studi Kasus Data Curah Hujan. 1(x), 1-7. http://www.ejurnal.ukrimuniversity.ac.id
Yamit. (2008). Manajemen Produksi dan Operasi. Yogyakarta: Ekonesia Fakultas Ekonomi UII. 